\title{
Análise da abordagem metodológica: um estudo dos Trabalhos Finais de Graduação em Design de Ambientes da EBA/UFBA
}

\author{
Analysis of the methodological approach: a study of the Final Graduation Works in \\ EBA/UFBA Design of Environments
}

HERNÁNDEZ, Maria Herminia Olivera; Doutora em Arquitetura e Urbanismo; EBA/UFBA

herminia@ufba.br

SANTOS, Victor Hugo Carvalho; Doutorando em Artes Visuais; PPGAV/EBA/UFBA

victorcarvalhoarq@gmail.com

SANTOS, Emyle dos Santos; Doutoranda em Artes Visuais; PPGAV/EBA/UFBA

emyles@ufba.br

FADIGAS, Larissa Braga de Melo; Mestra em Artes Visuais; EBA/UFBA

larissa.fadigas@ufba.br

\section{Resumo}

Com o objetivo de analisar a abordagem metodológica dos trabalhos finais de graduação em Design de Ambientes da Escola de Belas Artes da Universidade Federal da Bahia do período de 2015 a 2017, desenvolveu-se este artigo, que pode ser classificado como uma pesquisa descritiva, onde foram utilizadas as estratégias: bibliográfica, documental e ex-post facto, com base nos dados primários procedentes dos trabalhos produzidos no referido período. O enquadramento metodológico foi definido em cinco categorias de análises: quanto aos objetivos, abordagem do problema, abordagem das estratégias, métodos e ambiente de pesquisa, analisados descritivamente a partir da sistematização estatística. A correlação estatística proposta, cuja hipótese foi baseada na transdisciplinaridade, teve como variáveis concomitantes a frequência das disciplinas relacionadas e o grau de inovação presente nas pesquisas. Conclui-se que o conhecimento produzido pelas monografias analisadas apresenta fundamentos metodológicos promissores na busca por uma filiação cada vez mais engajada nos princípios da pesquisa contemporânea.

Palavras Chave: design de ambientes; abordagem metodológica; graduação em design de interiores e pesquisa em design de interiores.

\section{Abstract}

Establishing as the main goal to analyze the methodological approach of the final works of graduation in Design of Environments within the School of Fine Arts of the Federal University of Bahia from the period of 2015 to 2017, this article was developed, which can be classified as a descriptive research, where the following strategies were used: bibliographical, documentary and ex-post facto, based on the primary data from the works produced in the mentioned period. The methodological framework was defined in five categories of analysis: concerning the approach of the objectives, approach of the problems, approach of the strategies, methods and research environment, analyzed descriptively from the statistical systematization. The proposed statistical correlation, whose 
hypothesis was based on transdisciplinarity, had as concomitant variables the frequency of related disciplines and the degree of innovation exposed in the research. It is concluded that the knowledge produced by the analyzed works presents promising methodological foundations in the search for a filiation increasingly engaged in the principles of contemporary research.

Keywords: design of environments; methodological approach; graduation in interior design and research in interior design.

\section{Introdução}

Verifica-se no Brasil o aumento de cursos voltados para o design de interiores ${ }^{1}$, de acordo com os dados do Ministério da Educação e Cultura - MEC (2018), de 2015 a 2018 houve um aumento de 18 instituições de ensino que possuem tal curso. Em 2018 existem 21 estados mais o Distrito Federal com instituições de ensino oferecendo o curso de design de interiores, totalizando 152 cursos, dos quais, 124 são voltadas à formação tecnológica; 12 correspondem a cursos de bacharelado; 1 de licenciatura; 1 curso sequencial e 14 cursos tecnológicos na modalidade Ensino a Distância - EAD. Dos cursos de bacharelado, 4 se encontram em Universidades Federais e, entre os cursos tecnológicos, 4 são ofertados por Institutos Federais.

No que diz respeito a Programas de Pós-graduação Stricto Sensu voltados especificamente para o design de interiores, os registros são mínimos, verifica-se que os egressos deste campo do conhecimento inserem geralmente suas pesquisas em programas de áreas afins, tais como: artes, arquitetura, design, psicologia, entre outras, que abrangem estas investigações direta ou indiretamente através das suas áreas de concentração ou linhas de pesquisa. Dentro dessa perspectiva, outro aspecto sobre a Pós-graduação deve ser destacado, trata-se dos Programas Latu Sensu, segmento que congrega efetivamente vários cursos vinculados à nomenclatura design de interiores, focados na preparação do profissional para atuar com maior qualificação na sua área de conhecimento.

Dentro do contexto da formação, existe um aspecto crucial: a produção qualificada de publicações em design de interiores, que apesar de reportar avanços quantitativos e qualitativos na última década, abrindo caminhos para reflexões acerca da complexidade do mundo contemporâneo, ainda carece de estudos e discussões sobre temas relativos ao próprio campo. Nessa perspectiva os dados extraídos do $\operatorname{Scopus}^{2}$ (Gráfico 1) retificam a ideia de um crescimento destes temas, com base nas indexações de publicações ${ }^{3}$ recentes, tais como, artigos, dissertações e teses, nacionais e internacionais.

\footnotetext{
${ }^{1} \mathrm{O}$ termo design de interiores é a nomenclatura usual do campo, tanto em cursos quanto em publicações.

2 Scopus é a maior base de dados de resumos e citações de literatura científica revisados por pares. Fonte: www.americalatina.elsevier.com/sul/pt-br/scopus.php

${ }^{3}$ [...] Os livros nem sempre conseguem acompanhar as discussões devido a sua exigência temporal para editoração, compilação e muitas vezes, tradução,"[...] (SANTOS, 2016, p.17).
} 
Gráfico 1 - Publicações científicas de 1965 a 2015, utilizando a palavra-chave: interior design methodology.

Scopus

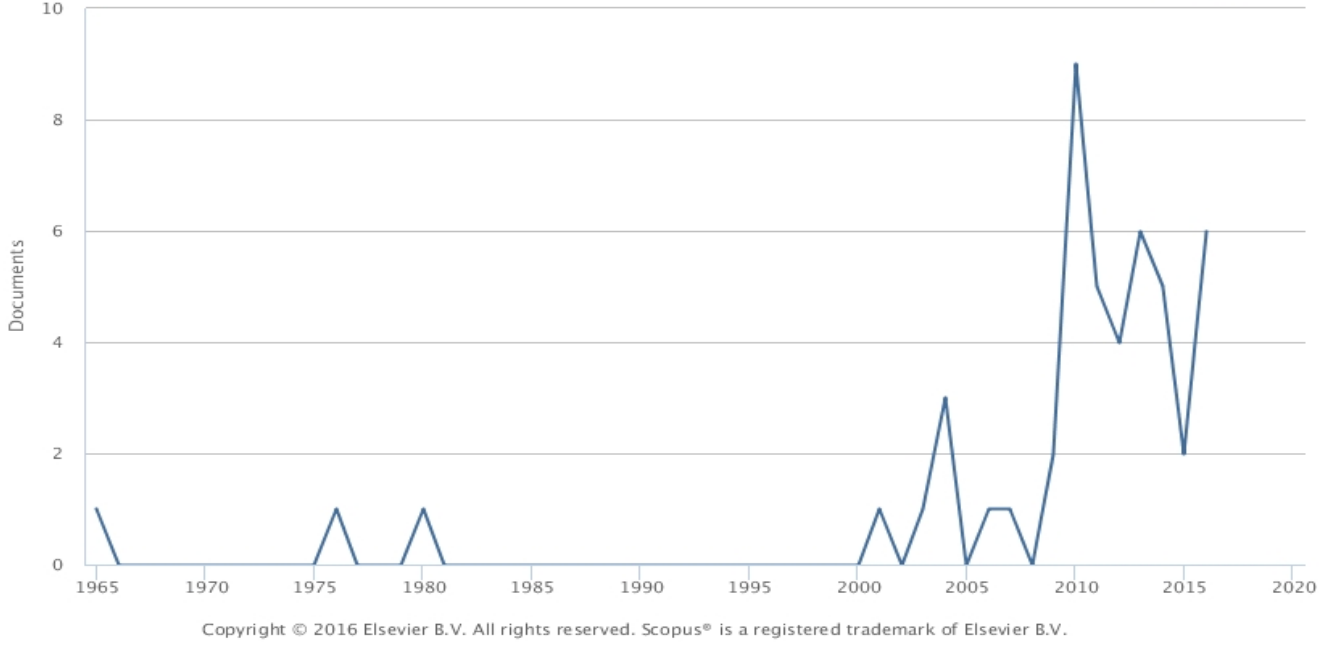

Fonte: Santos (2016, p.18)

No âmbito das publicações e pesquisas em design, considera-se como uma produção bibliográfica significativa aquela que resulta do Congresso de Pesquisa \& Desenvolvimento em Design, o P\&D. Evento cuja edição bianual traz investigações no campo do design como um todo, e dentro destas, o design de interiores. Tendo em vista sua relevância, foram consideradas algumas das informações obtidas do levantamento que compreende a produção resultante das três últimas edições, correspondendo aos anos de 2012, 2014 e 2016, realizado pelos próprios autores, no intuito de conhecer o estado da arte acerca da produção neste campo profissional. Das variáveis tratadas por esse levantamento interessaram aquelas referentes a: quantidade de trabalhos e os eixos temáticos de participação.

A 10ㅇ edição, ocorrida em 2012 na cidade de São Luís, no Maranhão e sediada pela Universidade Federal do Maranhão - UFMA, foi dividida em doze eixos temáticos e teve 565 artigos completos selecionados para a publicação nos anais. Daqueles, 26 artigos abordaram diretamente a relação com o campo do design de interiores, dentre eles $80 \%$ no eixo temático Design para Ambientes Construídos, os outros 20\% nos eixos: Design de Produto; Design Gráfico; e Design Sustentável. As temáticas mais recorrentes verificadas foram: design de exposição/cenografia, espaços infantis, hospitais e mobiliário.

O P\&D de 2014, aconteceu na cidade de Gramado, Rio Grande do Sul, com a co-realização da Escola Superior de Propaganda e Markenting - ESPM, de Rio Grande do Sul e o apoio das instituições anfitriãs Universidade Federal do Rio Grande do Sul - UFRGS, Universidade do Vale do Rio dos Sinos - UNISINOS e Centro Universitário Ritter dos Reis - UNIRITTER. Esta que foi a 110 edição, contou com 11 áreas temáticas, cujas publicações atingiram 322 artigos completos. Cabe mencionar que entre estes a ocorrência de trabalhos com temáticas relacionadas ao campo do design de interiores é pouco expressiva, sendo localizados três artigos que abordam diretamente questões dessa natureza, representando assim, aproximadamente $1,073 \%$ das publicações. Desses 3, cada um se insere em um eixo temático, sendo eles: Teoria e Crítica do Design; Design e Tecnologia; e Design e Educação. 
A última edição trabalhada foi o 12 P\&D, de 2016, sediado pela Universidade do Estado de Minas Gerais - UEMG, na cidade de Belo Horizonte. Foram publicados 458 artigos completos, dentre estes, 22 artigos trataram especificamente de design de interiores, o que corresponde a 4,8\% dos trabalhos selecionados, sendo distribuídos entre 5 dos 6 eixos temáticos do evento, são eles: História, Teoria e Crítica do Design; Metodologias do Design; Design e educação; Design e Processos Sociais; e Práticas do Design.

Com a sistematização das três edições do P\&D foi percebida uma perspectiva de aprofundamento no conteúdo dos trabalhos apresentados, apontando a compreensões mais complexas acerca do design de interiores que envolvem aspectos bastante promissores, que vão desde a busca pelas especificidades da área, até a constatação de seu potencial para a inter e transdisciplinaridade, observada a partir dos eixos de inserção no evento e a partir das temáticas e do referencial utilizado nas discussões. De forma geral, observa-se que os artigos analisados possuem rigor científico, uma vez que colocam de forma clara os objetivos, a abordagem dos problemas e os métodos de procedimento. Entretanto, cabe sublinhar que o pequeno número de artigos publicados nessas edições evidencia a fragilidade antes mencionada, no caso, a escassez de pesquisas sobre os temas relativos ao design de interiores e seu foco sobre aspectos relacionados às abordagens metodológicas no campo.

Diante do contexto descrito, pode-se afirmar que o problema que motiva esta pesquisa consiste na carência de estudos aprofundados que tratem acerca de investigações em design de interiores, em particular daqueles que tratam da abordagem metodológica e dos aspectos transdisciplinares nelas presentes. Assim considera-se relevante investir em um tema que possibilite investiga-la, considerando para isso os trabalhos defendidos entre 2015.1 e 2017.2, que neste estudo serão identificados como monografias, no intuito de enquadrar os mesmos quanto à abordagem metodológica empregada e quanto a transdisciplinaridade das propostas, visando ampliar o universo dos estudantes com relação à reflexão crítica e uso de métodos de projeto na prática projetual em design de interiores. Este período de escolha se fundamenta em razões didático pedagógicas do curso de Design de Ambientes ${ }^{4}$ da Escola de Belas Artes da Universidade Federal da Bahia que desde 2015. 1, optou por fazer a transição do trabalho da disciplina Prática Profissional do curso à Trabalho de Conclusão de Curso (TCC), condição que ficará finalmente reconhecida com a implantação da reforma curricular atualmente em processo.

O estudo está estruturado em cinco seções: a primeira aborda questões introdutórias e relativas aos problemas pesquisados; a segunda apresenta os procedimentos adotados que servem de fundamento à investigação; a terceira se debruça nas análises das abordagens metodológicas e os aspectos da transdisciplinaridade demostrando dados, gráficos e reflexões acerca do fenômeno estudado; a quarta aborda a transdisciplinaridade como um saber considerado na ordem do saber complexo em concordância com a contemporaneidade; e a quinta que traz as considerações finais acerca da pesquisa.

\section{Procedimentos Metodológicos da Pesquisa}

\subsection{Tipologia da pesquisa}

Toda pesquisa segue em essência procedimentos que possibilitam a produção de um

\footnotetext{
${ }^{4}$ Optou-se por identificar o curso como Design de Ambientes, tendo em vista que o curso, em processo de reformulação curricular, passará a ser identificado dessa forma.
} 
determinado conhecimento acerca de um fenômeno estudado. Nesse sentido, cabe destacar que a metodologia reconhecida como o estudo dos métodos ou processos racionais para chegar a uma determinada solução de projeto, tem como objetivo refletir acerca dos diversos métodos disponíveis e verificar suas possibilidades de aplicação. Aliado ao conceito do método comparecem as técnicas de pesquisa que se configuram nos instrumentos suportes do método na busca do resultado desejado, e o referencial teórico base. A concordância desses elementos evidência a metodologia da pesquisa. Convêm observar que a produção do conhecimento atual deve estar aliada à discussão contemporânea acerca do método, que,

[...] busca um pensamento transdisciplinar, um pensamento que não se quebre nas fronteiras entre as disciplinas. $O$ que interessa é o fenômeno multidimensional e não a disciplina que recorta uma dimensão deste fenômeno. Tudo o que é humano é ao mesmo tempo psíquico, sociológico e econômico, histórico, demográfico. (MORIN apud PÁDUA, 2004, p.28)

Esse pensamento contemporâneo, complexo, envolve a discussão e reflexão de elementos antes não levados em conta pela ciência, conhecida como clássica, isto é, aqueles que penetram em instâncias de ordem intangível compreendendo as realidades dos sujeitos ao longo da história. Este aspecto será retomado na quarta seção deste trabalho.

A seguir (Quadro 1), apresentam-se elementos da abordagem metodológica e seus desdobramentos voltados a uma melhor compreensão da presente proposta.

Quadro 01: Elementos da abordagem metodológica

\begin{tabular}{|c|c|c|c|c|c|}
\hline \multirow[t]{2}{*}{ Objetivos } & \multirow{2}{*}{$\begin{array}{c}\text { Abordagem do } \\
\text { problema }\end{array}$} & \multirow{2}{*}{$\begin{array}{l}\text { Estratégias da } \\
\text { pesquisa }\end{array}$} & \multicolumn{2}{|c|}{ Métodos } & \multirow{2}{*}{$\begin{array}{c}\text { Ambiente da } \\
\text { pesquisa }\end{array}$} \\
\hline & & & $\begin{array}{l}\text { Método de } \\
\text { Abordagem }\end{array}$ & $\begin{array}{l}\text { Métodos de } \\
\text { procedimento }\end{array}$ & \\
\hline $\begin{array}{l}\text { Dependem da } \\
\text { aproximação e do } \\
\text { nível conceitual } \\
\text { do pesquisador } \\
\text { em relação ao } \\
\text { estudo. }\end{array}$ & $\begin{array}{l}\text { Depende das } \\
\text { variáveis } \\
\text { compreendidas } \\
\text { pelo estudo. }\end{array}$ & $\begin{array}{l}\text { Formas pela } \\
\text { qual se leva o } \\
\text { estudo e se } \\
\text { coletam os } \\
\text { dados. }\end{array}$ & $\begin{array}{l}\text { Base lógica da } \\
\text { pesquisa. } \\
\text { Considera uma } \\
\text { abordagem mais } \\
\text { ampla e elevada } \\
\text { do fenômeno } \\
\text { estudado. }\end{array}$ & $\begin{array}{l}\text { Pressupõem uma } \\
\text { postura especifica } \\
\text { em relação ao } \\
\text { fenômeno } \\
\text { estudado. }\end{array}$ & $\begin{array}{l}\text { Refere ao } \\
\text { local onde o } \\
\text { pesquisador } \\
\text { busca seus } \\
\text { dados. }\end{array}$ \\
\hline - Exploratórias & $\begin{array}{l}\text { - Pesquisa } \\
\text { quantitativa }\end{array}$ & - Bibliográfica & - Dedutivo & - Histórico & - Campo \\
\hline - Descritivas & $\begin{array}{l}\text { - Pesquisa } \\
\text { qualitativa }\end{array}$ & - Documental & - Indutivo & - Comparativo & - Laboratório \\
\hline - Analíticas & $\begin{array}{l}\text { - Quali- } \\
\text { quantitativa }\end{array}$ & -Levantamento & $\begin{array}{l}\text { - Hipotético- } \\
\text { dedutivo }\end{array}$ & $\begin{array}{l}\text { - Monográfico } \\
\text { (Estudo de caso) }\end{array}$ & - Bibliografia \\
\hline & & - Experimental & - Dialético & - Tipológico & \\
\hline & & - Ex post facto & & - Funcionalista & \\
\hline & & - Pesquisa ação & & & \\
\hline & & - Estudo de caso & & & \\
\hline
\end{tabular}

Fonte: autores (2018), baseados em Marconi; Lakatos (2001), Martins; Linden (2012) e Santos (2004)

Para atingir o objetivo aqui proposto, optou-se pelo desenvolvimento de um estudo indutivo, quanto ao método de abordagem, já que possibilita uma leitura ascendente sob o fenômeno abordado, pois, a observação dos padrões identificados nas particularidades das monografias, 
objeto de análises, possibilitarão uma generalização a respeito deste fato, podendo assim, gerar reflexões importantes para o desenvolvimento desta prática.

Quanto ao problema, considera-se uma pesquisa que conjuga elementos quantitativos e qualitativos, por analisar tanto os aspectos estatísticos quanto sua interpretação qualitativa. Neste sentido, o trabalho sistematiza os dados, traçando um panorama fenomenológico das pesquisas analisadas na Escola de Belas Artes da Universidade Federal da Bahia, para então, inferênciar sob a relação transdisciplinar destas.

Quanto aos objetivos configura-se em uma pesquisa descritiva, de maneira que se propõe a descrever e analisar as observações objetivas e diretas dos aspectos metodológicos da produção científica no campo do design de interiores no curso de Design de Ambientes da Escola de Belas Artes da Universidade Federal da Bahia. Acerca dos procedimentos, trata-se de pesquisa bibliográfica, documental e ex post facto, uma vez que trabalha com materiais ainda não analisados em profundidade. A técnica da coleta de dados parte de fontes primárias, pois as monografias em análise ainda não foram estudadas na perspectiva e objetivos aqui focalizados, sendo por tanto, uma abordagem antes não realizada.

\subsection{Delimitação da amostra de análise}

A investigação tem como recorte o período de 2015 a 2017, as balizas temporais indicadas têm sua fundamentação nas razões didático pedagógicas inerentes ao curso de Design de Ambientes citadas na seção introdutória da presente pesquisa. Após a verificação da populaçãoalvo, 26 trabalhos, consistente na totalidade das monografias defendidas, consideraram-se como categorias de análise do fenômeno: objetivos das pesquisas, abordagem do problema, estratégias de pesquisa, métodos e seu ambiente. Optou-se por não delimitar uma amostra neste caso, pela possibilidade da não representatividade da população, bem como por almejar propor correlações entre as variáveis de pesquisa, sendo assim, uma redução de dados implicaria em uma correlação enfraquecida do fenômeno.

\subsection{Procedimento de coleta e análise dos dados}

As pesquisas encontram-se depositadas no Laboratório de Investigação de Materiais, o LIM, da Escola de Belas Artes da Universidade Federal da Bahia. Conforme os propósitos da investigação, adotou-se como técnica a análise de conteúdo, seguida de análise estatísticas que auxiliassem na sistematização e interpretação destes dados. Para este processo de coleta estatístico, utilizou-se Crespo (2002) Larson e Farber (2010) como base teórica, partindo para uma coleta direta periódica, das monografias defendidas nos anos de 2015, 2016 e 2017.

Em seguida foi realizada uma crítica interna dos dados elencados, estabelecendo-se para isso, critérios avaliativos que nortearam a quantificação das variáveis. Estes critérios foram pautados nos parâmetros metodológicos científicos de Santos (2004) e Marconi e Lakatos (2001), gerando como análise, um panorama descritivo do fenômeno. Também se observou a frequência de áreas disciplinares utilizadas nas monografias e se quantificou o atendimento aos critérios de avaliação para inovação de Garcia (2008), tendo como saída, a análise da correlação transdisciplinar entre estas variáveis.

\section{Análise específica}

Cumpre a esta seção, as análises das abordagens metodológicas das pesquisas citadas, para 
tal, foi averiguado cada elemento do enquadramento metodológico, a fim de traçar um entendimento categorizado do fenômeno.

\subsection{Quanto aos objetivos}

Santos (2004, p.25) afirma que as pesquisas conforme os objetivos [...] "podem ser caracterizadas como exploratórias, descritivas ou analíticas". Sob esse ponto de vista e segundo os dados coletados, de acordo com o Gráfico 2, percebe-se que existe um equilíbrio quanto aos objetivos das pesquisas analisadas.

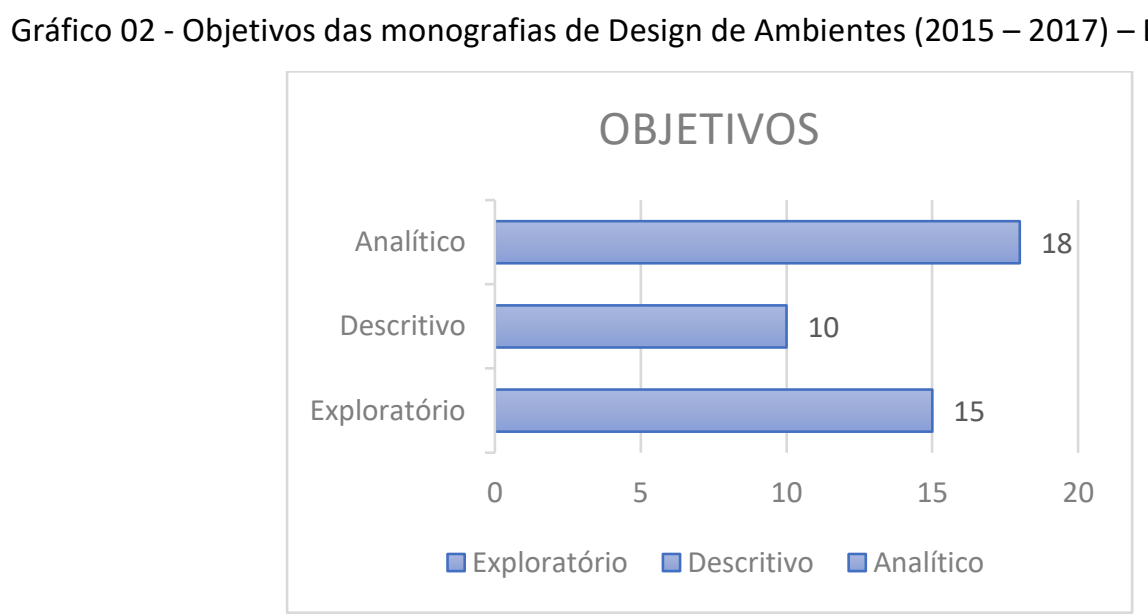

Fonte: autores (2018)

Neste sentido, observa-se que muitas das pesquisas possuem múltiplos vieses, podendo assumir mais de uma categoria quanto ao seu objetivo. Comprovando a preferência, dos estudantes e orientadores de monografias, em aprofundar o estudo das informações disponíveis na busca por explicar o contexto do fenômeno, aproximando-se basicamente das categorias histórica e de revisão. Daí a correspondência direta da investigação analítica e descritiva com a pesquisa exploratória, que pela sua essência se adentra em levantamentos e exemplos, entre outras técnicas visando o fenômeno estudado.

\subsection{Abordagem do problema}

Dependendo das variáveis compreendidas pelo estudo as pesquisas podem ser qualitativas, quantitativas e quali-quantitativas. A partir da análise realizada foi constatado que a maioria das pesquisas se caracterizou pela investigação qualitativa, demonstrando uma melhor compreensão dos estudantes do fenômeno no contexto do qual é parte e visando uma perspectiva de análise integrada do mesmo. Este resultado tem correspondência com a categoria anterior analisada referente aos objetivos, e tem relação com as categorias seguintes tratadas no presente artigo. Registra-se que a ocorrência da modalidade quali-quantitativa foi mínima e não teve estudos apenas quantitativos.

\subsection{Abordagem das estratégias}

As estratégias de pesquisa estão voltadas à maneira pela qual se leva o estudo e se coletam dados para serem posteriormente tratados. Conforme Santos (2004), as estratégias mais comuns são a pesquisa bibliográfica, pesquisa documental, levantamento, pesquisa experimental, pesquisa 
ex post facto, pesquisa ação e estudo de caso. Constata-se no Gráfico 3 a frequência dessas estratégias nas monografias analisadas.

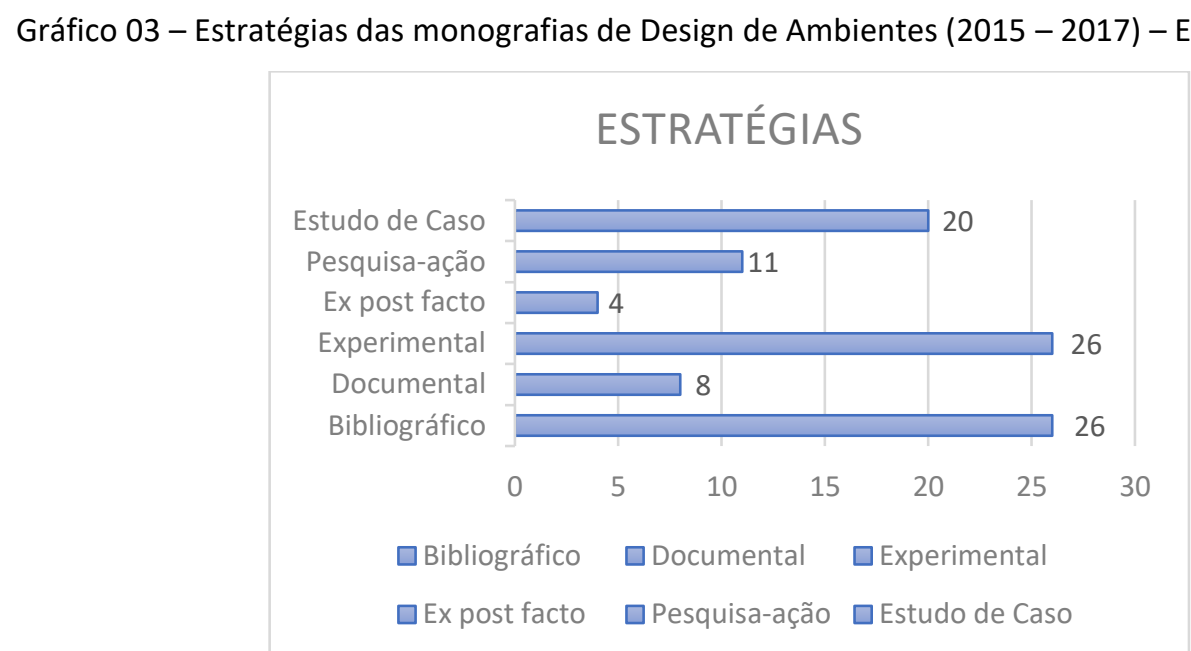

Fonte: autores (2018)

Assim como no gráfico referente aos objetivos, muitos dos discentes optaram por estratégias diferentes para a resolução dos projetos. O Gráfico 3 mostra ainda, que todos os integrantes da população privilegiaram as estratégias bibliográficas e experimentais, muito coerente com a proposta do trabalho final de graduação, que visa a produção de uma pesquisa cientifica além da exigência experimental, por meio dos projetos, dos conceitos apreendidos na monografia e durante o curso.

O estudante deve, portanto, demonstrar tanto o domínio da linguagem técnica quanto a aptidão para o desenvolvimento reflexivo e crítico sob o tema. Ademais, identificou-se a presença de estudos de caso, pela possibilidade de análise crítica e da aquisição de conhecimentos específicos. Ao mesmo tempo, nota-se que poucas pesquisas foram desenvolvidas sob a estratégia ex post facto, devido, principalmente, à dificuldade de observar e analisar um fato ocorrido, no curto período de execução da monografia, para tal, seria preciso uma delimitação bem clara e estratégias focadas e precisas de desenvolvimento, visando, inclusive, um tempo mais dilatado para a realização das pesquisas. Considera-se que no viés dessa estratégia pode ser aberto um caminho futuro para pesquisas inéditas e originais.

\subsection{Métodos}

Dentro da variável métodos, considerou-se os métodos de abordagem, sendo estes os responsáveis pelo raciocínio que será utilizado no desenvolvimento da pesquisa, focalizando nos clássicos: dedutivo, hipotético-dedutivo, indutivo e dialético. Dentro da população estudada verificamos uma preferência pelas abordagens hipotético-dedutivas e dedutivas (Gráfico 4), compreendo assim, que para os estudantes do curso de Design de Ambientes da EBA/UFBA é mais interessante partir de uma generalização para um aspecto específico relacionado ao seu tema, do que o inverso. Seguindo essa argumentação pode-se aferir que isso ocorre porque quase todas as monografias tentam refletir primeiro sobre o fenômeno geral da profissão do designer de interiores, compreendendo a sua identidade, para em seguida abordar um problema específico deste ou mesmo propor, uma hipótese para dedução que mais adiante é tratada e/ou processada no estudo 
de caso, o qual traz a reboque aproximações específicas de coleta e análise de dados, muitos em consonância com a interdisciplinaridade e transversalidade.

Gráfico 04 - Métodos de pesquisa das monografias de Design de Ambientes (2015 - 2017) - EBA/UFBA

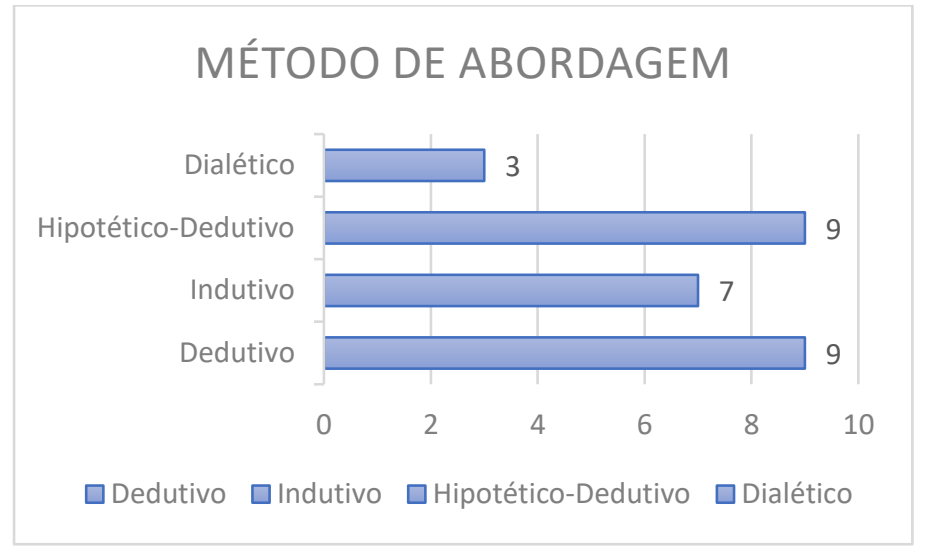

Fonte: autores (2018)

Dando prosseguimento, pontuam-se os métodos de procedimento, considerados etapas mais concretas da investigação e diferentes dos métodos de abordagem, na sua finalidade mais restrita quanto a explicação geral dos fenômenos, e ainda para alguns autores como Marconi e Lakatos (2001), apenas pelo seu uso mais abrangente, passaram de técnicas à categoria de métodos. No Gráfico 5, verifica-se o uso simultâneo dos diversos métodos, o que demonstra os vários enfoques adotados pelos estudantes na abordagem do objeto de estudo.

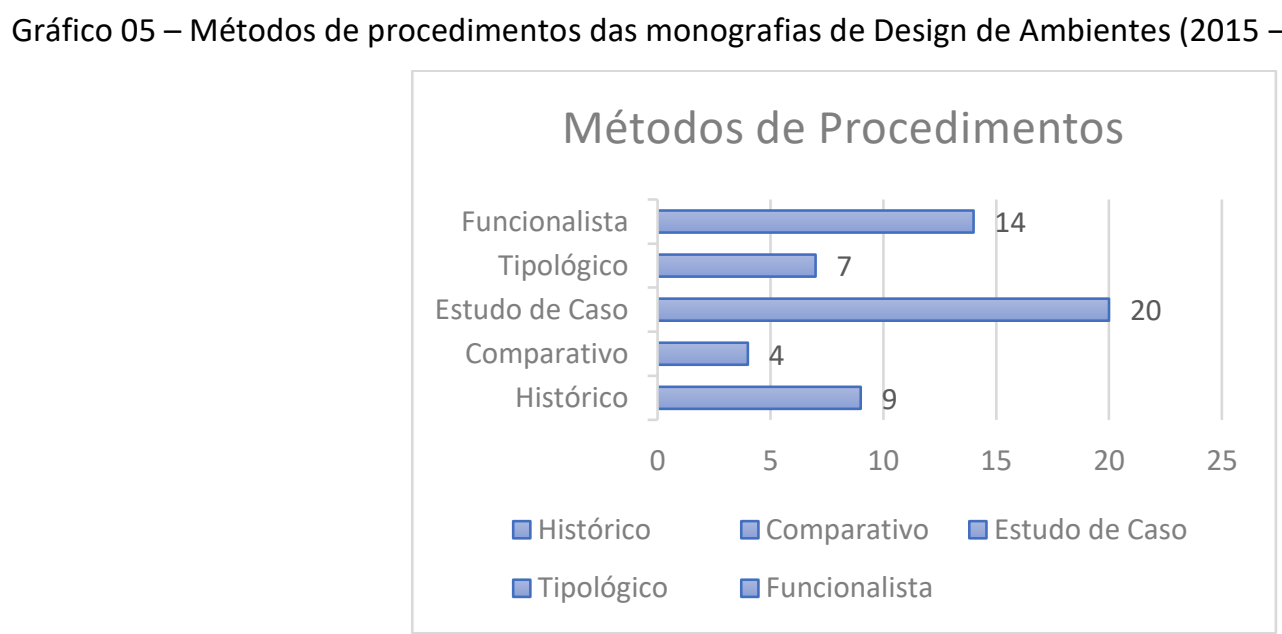

Fonte: autores (2018)

No tocante ao estudo de caso como o método de procedimento mais utilizado, pode-se afirmar que se trata de uma evidência consoante com a prática projetual em design de interiores que regularmente recorre à investigação do tema observando todos os fatores que o influenciam, analisando-o em todos os seus aspectos, abrangendo para isso abordagens específicas de coletas e análise de dados que, no caso das pesquisas oriundas da população estudada integram outros métodos e técnicas, tais como design emocional, sonda cultural, etnografia, entre outros. 


\subsection{Ambientes de pesquisa}

O ambiente da pesquisa diz respeito ao local onde o pesquisador busca seus dados, servindo como fonte de pesquisa os lugares e situações dos quais podem ser coletados os estudos necessários para a pesquisa. Segundo Santos (2004) as fontes dos dados são três: o campo, o laboratório e a bibliografia. Diante do fenômeno analisado, adaptou-se o campo enquanto ambiente ao qual o designer de interiores lança sua proposta de pesquisa; o laboratório como meio de experimentação do mesmo e a bibliografia enquanto a procedência das fontes citadas. Estes ajustes foram feitos a fim de observar os campos, laboratórios e bibliografias mais escolhidas, no sentido de estimular ambientes pouco explorados como tema para outras pesquisas.

Fica evidente no Gráfico 6 a primazia do ambiente residencial enquanto objeto de estudo das pesquisas, estando presente em $42 \%$ dos trabalhos, seguida do educacional, com $23 \%$, e da comercial, com $19 \%$. Ficando os outros ambientes, religioso, paisagismo, saúde e efêmero, com $4 \%$. Percebe-se uma realidade que traduz aspectos do processo de formação onde metade das propostas projetuais trabalhadas durante o curso se debruçam sob a perspectiva do ambiente residencial, sublinhando que, no caso das pesquisas analisadas corrobora-se o estabelecimento de diversas problemáticas que extrapolam, inclusive a natureza inerente ao uso tradicional da morada como o lugar de habitar. Contudo, interessa incluir que o dado aponta para a necessidade do incentivo aos estudantes pela busca de outros ambientes e problemáticas.

Gráfico 06 - Ambientes abordados nas monografias de Design de Ambientes (2015 - 2017) - EBA/UFBA

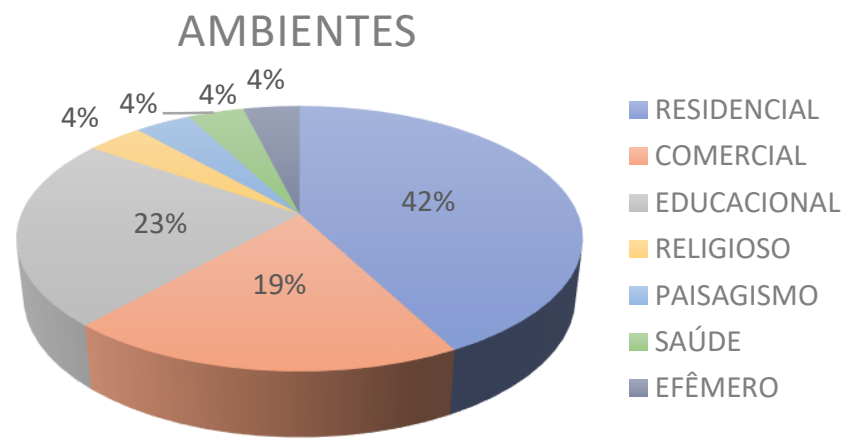

Fonte: autores (2018)

Quanto a procedência bibliográfica, percebe-se (Gráfico 7) a fonte de informação consultada, onde os dados indicaram uma grande quantidade de livros e informações obtidas em páginas de internet, em seguida os artigos científicos foram a terceira fonte de informação mais arrolada, seguido muito de perto por normas técnicas ${ }^{5}$ e documentos. Verifica-se que as dissertações de mestrado aparecem também como uma fonte relevante de pesquisa e por último, ainda de forma muito tímida, as monografias de graduação, teses de doutorado, monografias de

\footnotetext{
5 As normas técnicas encontradas nas monografias dizem respeito a consultas de parâmetros para ambientes construídos, a citar ABNT. Entende-se que esse referencial é relevante para a prática profissional, sobretudo no que concerne aos aspectos técnicos relacionados a: antropometria, proxêmica, ergonomia, entre outros.
} 
especialização e revistas.

Gráfico 07 - Procedências bibliográficas citadas nas monografias de Design de Ambientes (2015 - 2017) - EBA/UFBA

\section{PROCEDÊNCIA BIBLIOGRÁFICA CITADA}
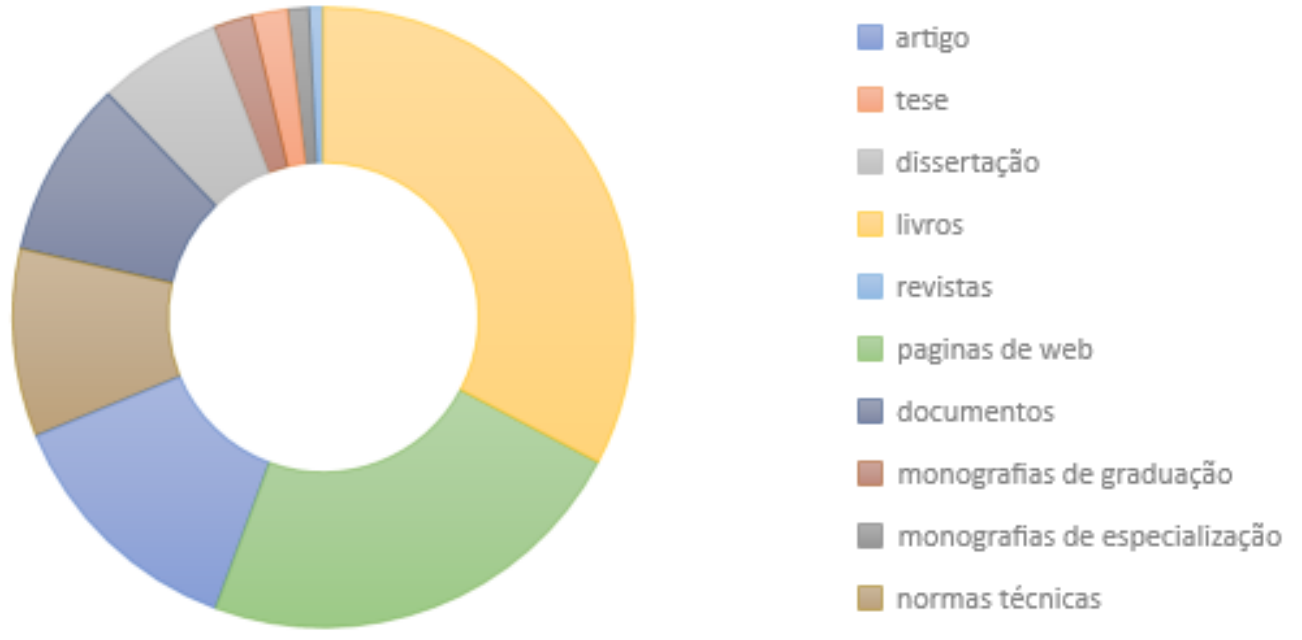

Fonte: autores (2018)

O laboratório como meio de experimentação para o design de interiores se configura no âmbito onde dados, reflexões e análises diversas são reproduzidos e processados adquirindo formas diferentes de apresentação que transitam pelos textos, representações gráficas e imagéticas nas suas diversas modalidades até as maquetes e protótipos, sejam eles físicos ou virtuais.

\section{Transdisciplinaridade como correlação}

A construção desta pesquisa almeja analisar um fenômeno de cunho científico, que é a prática do trabalho final de graduação do curso de Design de Ambientes da Escola de Belas Artes da Universidade Federal da Bahia. Como apontado antes na introdução, além deste ser um fenômeno recente para o curso (2015-2017), o campo do design de interiores, como um todo, ainda se encontra pouco explorado pelas pesquisas brasileiras, bem como a maior parte desta produção é de cunho tecnicista/funcionalista (SANTOS, 2016). Assim, as reflexões acerca da área, ainda são pontuais e dispersas, mas em constante crescimento, tanto demonstrado pelo próprio fenômeno aqui estudado quanto pelas estatísticas de publicação na área. Para facilitar o processo de fertilização desta produção científica, crítica e reflexiva, como apontado antes, é necessário compreender, como a ciência está se desenvolvendo contemporaneamente, a fim de traçar perspectivas que podem ser inclusivas e fomentadoras do fenômeno e contexto aqui analisado.

Nesse viés, entende-se a ciência, como sendo uma atividade que busca conhecer, explicar, prever e modificar determinados processos, assim, a ação do homem de inventar hipóteses, pesquisar, realizar experimentos e gerar resultados que construam conhecimento, são as suas principais estratégias. Não se trata aqui de discorrer sobre a evolução científica, mas sim, compreender alguns marcos que reverberam diretamente no presente estudo. Neste ponto, Alvarenga, Sommerman e Alvarez (2005) fornecem alguns argumentos, ao afirmarem que a ciência e a sua produção, passou e passará, por quatro grandes grupos de caráter: enciclopédico, disciplinar, interdisciplinar e transdisciplinar. Quando os mesmos autores, se referem ao 
conhecimento disciplinar, estão localizando seu surgimento no período moderno, que rompe o passado enciclopedista e cria disciplinas específicas de estudo. Com o passar dos anos, para que estes saberes avancem, foi proposta a abordagem interdisciplinar, que opera pela interação colaborativa de disciplinas, com o intuito de neste diálogo, identificar respostas diferentes para um mesmo aspecto.

Contemporaneamente, a transdisciplinaridade emerge enquanto iniciativa científica, assim como a interdisciplinar, propõe diálogos entre as disciplinas, no entanto, a diferença reside no fato do saber transdisciplinar propor trocas interdisciplinares sob problemas diferentes:

Nessa perspectiva, a transdisciplinaridade não nega o disciplinar uma vez que parte do disciplinar, mas o relativiza, constituindo-se num saber que organiza diferentes saberes necessita e propõe o encontro entre o teórico e o prático, entre o filosófico e o científico, apresentando-se, assim, como um saber que é da ordem do saber complexo. A partir de tais concepções é possível considerar que a busca dos fundamentos para uma abordagem transdisciplinar passe, necessariamente, pelo reconhecimento de que o eixo da ciência contemporânea seja, de acordo com Morin (1996), o da complexidade. (ALVARENGA; SOMMERMAN; ALVAREZ, 2005, p.16)

Com base nesta ideia, buscando reconhecer também a abordagem cientificista do fenômeno aqui analisado, propõe-se uma correlação estatística, entre as áreas de conhecimento disciplinar citadas nas monografias do curso de Design de Ambientes e os aspectos inovadores que estas pesquisas apresentaram, já que, como área ainda pouco explorada cientificamente, seria interessante descobrir primeiro, como este saber está sendo construído.

Segundo Larson \& Farber (2010) a correlação estatística é um procedimento metodológico inferencial, que tem como objetivo, identificar uma relação entre duas variáveis independentes e caso ela exista, sua taxa de associação. Vale salientar que a correlação não pode ser tomada enquanto interpretação causal, suas variáveis são independentes e para que fossem analisadas enquanto causa/consequência, seriam necessários métodos mais complexos de análise. No entanto, a correlação é suficiente pois ela permite a identificação da concomitância entre as variáveis, sendo este um dos interesses principais desta pesquisa.

Neste sentido, lançou-se a hipótese de que dentro da transdisciplinaridade, duas variáveis trabalham em correlação, a primeira delas a independente, que diz respeito ao carácter multidisciplinar da pesquisa, quantificada pela frequência de disciplinas relacionadas nas monografias e a segunda, dependente, que verifica o grau de inovação que a pesquisa possui.

A escolha pela inovação foi feita, por julgar, assim como Garcia (2008), que está, ocorre quando se inventa algo novo, que promove novos horizontes a cerca de um determinado produto/serviço. Sendo assim, ao se falar de transdisciplinaridade como processo de avanço e desenvolvimento de novos conhecimentos, o carácter inovador possui relação conceitual direta, sendo uma variável dependente elegível.

Partindo destas escolhas e refinando seus parâmetros, foram consideradas as quinze áreas mais citadas nas monografias: arquitetura, design, artes, antropologia, etnografia, filosofia, sociologia, psicologia, sustentabilidade, administração, decoração, marketing, metodologia e história, como tabela de frequência quantitativa; os doze parâmetros inovadores do modelo de avaliação Radar: oferta, plataforma, soluções, clientes, experiências do cliente, valor capturado, processos, organização, cadeia de fornecimento, presença, rede e marca (GARCIA, 2008), adicionando a estes três novos parâmetros: conceito, soluções projetuais e articulação bibliográfica, 
estes últimos, mais específicos da inovação em design de interiores. Como resultado de teste para a hipótese, apresenta-se o Gráfico 8 a seguir.

Gráfico 8 - Correlação transdisciplinar observada nas monografias de Design de Ambientes (2015 - 2017) - EBA/UFBA

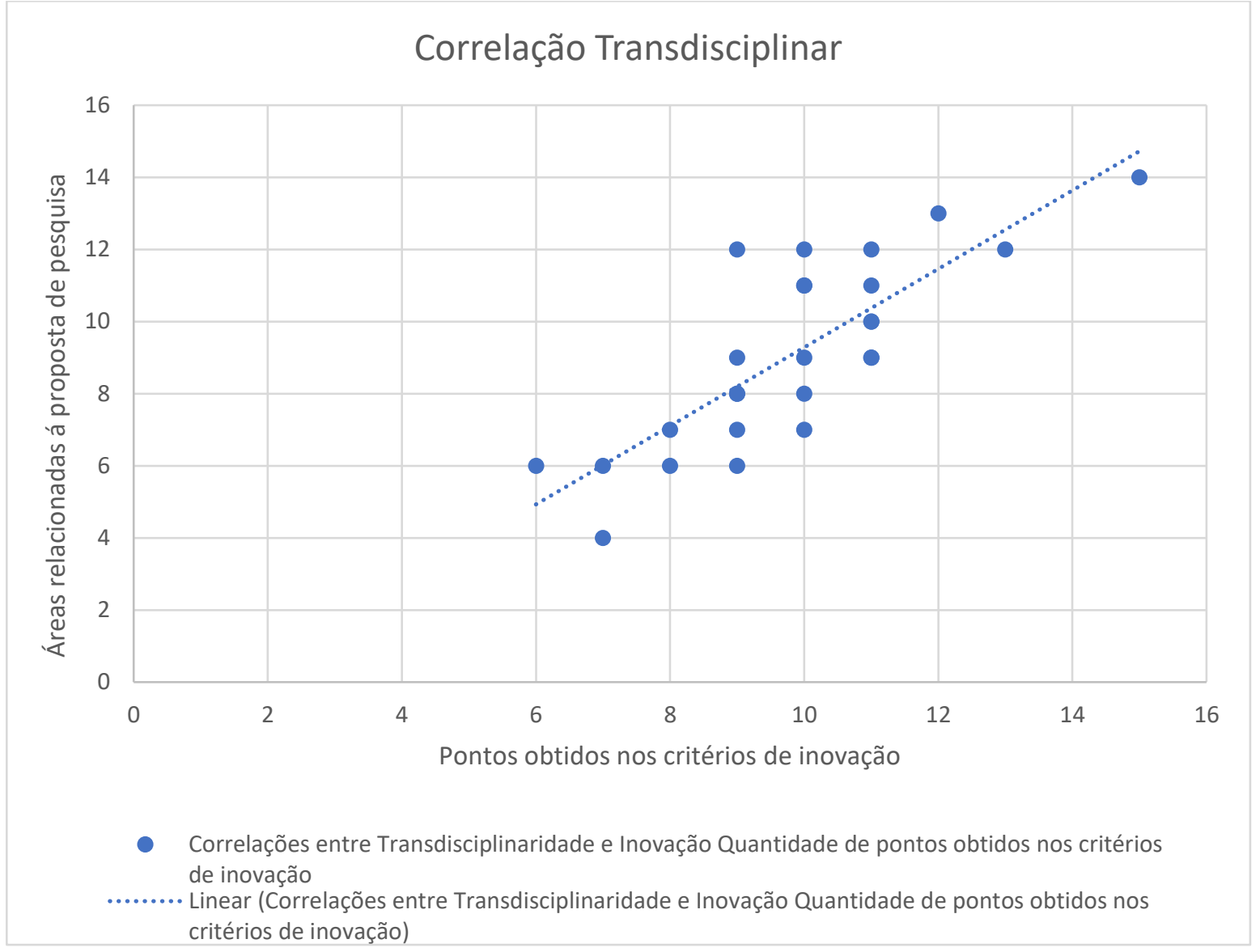

Fonte: autores (2018)

Pode-se interpretar, que as variáveis possuem uma correlação forte $(R=0,802)$ segundo a tabela de referência Pearson (SANTOS, 2007), o que indica uma alta concomitância entre as variáveis, comprovando assim que estas, se desenvolvem simultaneamente e tem proximidades de influência. Ademais, é notório pela regressão linear que a correlação assume o caráter positivo, inferindo que além de significantes, as variáveis progridem positivamente juntas, atestando assim, que a hipótese da relação entre as variáveis, existe e podem ser projetivas no sentido de que, monografias que contemplarem soluções inovadoras irão possuir múltiplas fontes de dados em áreas correlatas. Destarte, o estímulo dos orientadores e professores, por fontes de pesquisa transdisciplinares, auxiliará o estudante na probabilidade de alcançar resultados inovadores.

\section{Considerações Finais}

Confirma-se o significado que tem para o design de interiores a realização deste tipo de trabalho voltado às abordagens metodológicas vinculada aos aspectos transdisciplinares, considerada uma das formas possíveis de se refletir acerca da produção do conhecimento qualificado neste campo específico. Para o desenvolvimento da investigação foi indicada a 
população alvo, aqui identificada como as 26 monografias defendidas no trabalho de conclusão de curso dos estudantes do curso de Design de Ambientes da Escola de Belas Artes da Universidade Federal da Bahia, e a abordagem metodológica de seu enquadramento, demarcando-se então, as respostas para o quê, onde e como pesquisar, procedeu-se a realização das análises conforme as variáveis definidas. Seguida pela proposta de uma correlação estatística, que teve enunciada uma hipótese dentro da transdisciplinaridade, com duas variáveis uma independente e outra dependente.

Estas análises demonstraram que, em sentido geral, as monografias estudadas apontam para abordagens metodológicas nas quais, conforme os objetivos, são consideradas pesquisas analíticas; segundo a abordagem do problema, nomeadamente qualitativas; pelo viés das estratégias, é acentuado o perfil das pesquisas experimentais e bibliográficas; referente aos métodos, se destacam por apresentar métodos de abordagem dedutiva e/ou hipotético-dedutivo; e como métodos de procedimento o estudo de caso foi o mais empregado; no que diz respeito ao ambiente da pesquisa é notório o direcionamento das propostas para o ambiente residencial; quanto as fontes, a bibliografia e o laboratório foram as mais frequentes como bases do processo de criação em design de interiores. Também cabe colocar que a correlação estatística proposta, que teve como hipótese a transversalidade, evidenciou a correlação positiva no sentido de uma progressão concomitante entre as variáveis, a independente que diz respeito ao caráter multidisciplinar da pesquisa e a dependente que verifica o grau de inovação que a pesquisa possui. Nesse sentido pode-se afirmar que o conhecimento que vem sendo produzido pela área apresenta fundamentos metodológicos promissores na busca por uma filiação cada vez mais engajada nos princípios da pesquisa contemporânea.

Em geral, as monografias estudadas ofereceram um diagnóstico do que vem sendo produzido pelo curso de Design de Ambientes da EBA/UFBA, ficando evidente que houve no período dos três anos compreendidos pela pesquisa, um avanço qualitativo no que diz respeito ao direcionamento dos trabalhos para o uso de metodologias cada vez mais voltadas para os objetos de estudo específicos da área de conhecimento aqui tratada, observando-se ainda a aproximação, apropriação e compartilhamento de métodos e técnicas de diversas áreas do conhecimento. Nessa perspectiva cabe destacar a coerência entre esta produção e os artigos sobre design de interiores das três últimas edições do P\&D (2012, 2014 e 2016), tratadas também pelo presente estudo, no que se refere ao rigor científico e a transdisciplinaridade dos trabalhos, sobretudo quando se observa a amplitude da temática e o trânsito entre as áreas do conhecimento, visíveis através dos referenciais teóricos.

A maneira de contribuição, considera-se que o resultado desta pesquisa pode levar a reflexões mais aprofundadas acerca da produção científica em design de interiores, no sentido, inclusive de levar estes conteúdos às disciplinas de prática projetual, o que se reverterá no emprego cada vez mais sistemático de métodos e técnicas para a produção do conhecimento científico. Sugere-se a ampliação de pesquisas semelhantes que tratem investigações acerca da produção científica não apenas na perspectiva da abordagem metodológica, mais também, por exemplo em estudos que estabeleçam estágios comparativos e reflexivos sobre essa produção, aprofundando as análises sobre a produção contemporânea, propondo abordagens que oportunizem formas possíveis para avanços nos fenômenos estudados. 


\section{Referências}

ALVARENGA, Augusta; SOMMERMAN, Américo; ALVAREZ, Aparecida. Congresso Internacional sobre transdisciplinaridade: reflexões sobre emergência e convergências de ideias e ideais na direção de uma nova ciência moderna. In: Saúde e Sociedade v.14, n.3, p. 9-27, set-dez, 2005.

CONGRESSO BRASILEIRO DE PESQUISA E DESENVOLVIMENTO EM DESIGN, 10., 2012, São Luís. Anais P\&D 2012. São Luís: Editora EDUFMA, 2012. 9361 p. Disponível em: <http://www.peddesign2012.ufma.br/anais/>. Acesso em: 25 fev. 2018.

CONGRESSO BRASILEIRO DE PESQUISA E DESENVOLVIMENTO EM DESIGN, 11., 2014, Gramado. Anais P\&D 2014. Gramado: Blucher Design Proceedings, 2014. 3758 p. Disponível em: <http://www.proceedings.blucher.com.br/article-list/11ped-233/list\#event>. Acesso em: 27 fev. 2018.

CONGRESSO BRASILEIRO DE PESQUISA E DESENVOLVIMENTO EM DESIGN, 12., 2016, Belo Horizonte. Anais P\&D 2016. Belo Horizonte: Blucher Design Proceedings, 2016. 5612 p. Disponível em: <http://www.proceedings.blucher.com.br/article-list/ped2016-277/list\#articles>. Acesso em: 24 fev. 2018.

CRESPO, A. A. A natureza da Estatística. São Paulo: Saraiva, 2002.

GARCIA, Fernando Jarrais. Um estudo sobre as formas de inovação e os critérios de avaliação dos prémios de inovação. 2008, 139p. Dissertação (Mestrado) - Programa de Pós-Graduação em Administração, Universidade de Caxias do Sul, Rio Grande do Sul, 2008. Disponível em: < https://repositorio.ucs.br/xmlui/bitstream/handle/11338/323/Dissertacao\%20Fernando\%20J\%20 Garcia.pdf?sequence=1\&isAllowed=y>. Acesso em: 05 fev. 2018.

LAKATOS, Eva Maria; MARCONI, Marina de Andrade. Fundamentos de metodologia científica. 4. ed. São Paulo: Atlas, 2001.

LARSON, R. \& FARBER, E. Introdução à estatística. São Paulo: Pearson Prentice Hall, 2010.

MARTINS, Rosane; LINDEN, Julio Carlos (org.). Pelos caminhos do design: metodologia de projeto. Londrina: EDUEL, 2012.

MEC - Ministério da Educação. Instituições de Educação Superior e Cursos Cadastrados. 2018. Disponível em: http://emec.mec.gov.br/. Acesso em: 01 de mar. de 2018.

PÁDUA, Elisabete Matallo Marchesini de. Metodologia da pesquisa: Abordagem teórico-prática. Campinas-SP: Papirus, 2004.

SANTOS, Antônio Raimundo dos. Metodologia científica a construção do conhecimento. Rio de Janeiro: DP\&A, 2004.

SANTOS, Carla. Estatística Descritiva: Manual de Auto-aprendizagem. Lisboa: Edições Sílabo, 2007.

SANTOS, Victor Hugo Carvalho. Metodologias de projeto voltadas para a criatividade em design de interiores. 2016, 164p. Dissertação (Mestrado) - Programa de Pós-Graduação em Artes Visuais, Escola de Belas Artes, Universidade Federal da Bahia, Salvador, 2016. Disponível em: <http://www.ppgav.eba.ufba.br/dissertações>. Acesso em: 02 fev. 2018. 